Johnson, M., Shi, W., \& Shao, X. (2010). Exploring library service models at Fudan University and Appalachian State University: Experiences from an International Librarian Exchange program. International Information \& Library Review, 42(3), 186-194. doi:10.1016/j.iilr.2010.07.002 The version of record is available from Elsevier at: http://www/sciencedirect.com (ISSN: 1057-2317).

Keywords: librarian exchange programs | academic libraries - administration | China

\title{
Exploring Library Service Models at Fudan University and Appalachian State University: Experiences from an International Librarian Exchange Program
}

\author{
Megan Johnson, Weihua Shi, \& Xiaorong Shao
}

\begin{abstract}
In 2008, Fudan University Library (FDUL) in Shanghai and Belk Library and Information Commons at Appalachian State University (ASU) in Boone, North Carolina created a three-year librarian exchange program. The first pair of librarian exchanges occurred during the 2009-2010 academic year, with the Appalachian State librarian traveling to Fudan for five weeks during the Fall of 2009, and the first librarian from Fudan traveling to Appalachian State for five months in the spring and summer of 2010. This paper documents how the first exchanges revealed interesting similarities and differences in the academic library service models between the two universities which are illustrative of general similarities and differences between Chinese and American academic library services. The paper also discusses how any academic library can benefit from the experience of a librarian exchange program with a partner library in another country. The experience gained from these first exchanges confirms on an international level the basic assertion that a major role of an academic library is to support the university's curriculum. Moreover it can be extrapolated from discussions held between librarians of the two institutions that in both the United States and China the curriculum evolves in response to reforms on campus and to changing trends within the country's education system. It was also determined that the modes of library services in both cultures change as new technologies arise and that the pace of technological change within academic libraries is rapid and ongoing. Participants in the exchange discovered that there are strengths and weaknesses in both the ASU and FDUL service models and that the librarians from both systems can learn from one another and absorb best practices from their exchange partners. This paper reflects the views and experiences of the exchange librarians (Shi and Johnson) and also author Shao, who is a Chinese national working as a faculty fellow librarian at Appalachian State University.
\end{abstract}




\section{ARTICLE}

\section{Literature review}

The body of literature in English comparing the differences between service models at Chinese academic libraries and their American counterparts is limited, although several authors do address library service when discussing related topics. Liao (2004) gives the most in-depth treatment of the topic of the differences between service models at Chinese academic libraries and their American counterparts. She argues that traditional library culture in China is the root cause for the underdevelopment of user services in Chinese academic libraries. Liao attributes this problem to several factors, including a shortage of professionals trained in current useroriented approaches to librarianship. Liao states, "Although they have a sophisticated knowledge of information technologies, many library professionals continue to think in the mode of traditional librarianship and regard themselves more as custodians of books than as the servants of readers" (p. 114). Liao also believes things are changing for the better, and notes "the adoption of modern technology not only greatly expedites information retrieval by patrons, but also compels library administrators to formulate new policies and formats for the dissemination of knowledge" (p. 114).

Chen and Liu (2005) also comment on the service model in Chinese academic libraries stating, "It is a common consensus that library services in China are somewhat backward compared to their counterparts in North America. It remains true for archives and bookstores, as well. The concept of a subject librarian was only introduced in the late 1980s. Reference service is also a relatively new concept and practice" (pp. 124-125).

In a more recent paper Jiao, Zhuo, Zhou, and Zhou (2009) indicate that academic libraries in China and America share common issues, including "challenges of technological infrastructure; the high cost of journals and electronic resources; creating a quality and sustainable service; and maintaining a viable learning environment" (pp. 1-2).

Scherlen, Shao, and Cramer (2009) note the importance for librarians in the United States, "to establish and build ties with librarians in other countries, such as China. Benefits of an exchange could include sharing information about best practices, exchange of serial materials, and working together on mutually advantageous projects" (p. 1). This article shows that international library exchange programs and international cooperative efforts are not the sole domain of large research institutions, as it discusses Appalachian Library's internationalization efforts. 
Generally, it appears that an emphasis on customer service has been the norm longer in American academic libraries, but that Chinese academic libraries are changing quickly and making significant strides in service. As Wu and Huang (2003) state, "The quality of resources and services [in Chinese libraries] has been highly improved" (p. 253).

The call for improvement of library services in China came from a top government authority. In 1988, the Ministry of Culture in China designated the last week of each May as Library Public Service Week in an effort to promote public service and encourage the use of library resources and facilities among citizens. The guiding principles of library services in China are not much different from those in the U.S. According to Chen (2006), all libraries should provide the public with equal and fair access to their resources and facilities. At the same time, libraries strive to provide excellent service and appropriate collections for all users. One of the results of the increased emphasis upon better library public services in China and expanded use of technologies in Chinese libraries has been more mutually beneficial opportunities for international exchanges and collaboration between Chinese and American libraries.

\section{Fudan-Appalachian Exchange Program Agreement (FALEP)}

In May 2008, Fudan University Library in Shanghai and Belk Library and Information Commons in Boone, N.C. signed the Fudan-Appalachian Librarian Exchange Program Agreement (FALEP), with the exchanges scheduled to take place between 2009 and 2011. The program facilitates exploring librarianship in an international context and sharing ideas about library services and scholarly communication. The FALEP agreement allows for an exchange librarian from Fudan to be in residence at Appalachian and an Appalachian librarian to be in residence at Fudan University Library for one to six months each year.

Appalachian State University Library selected Megan Johnson, Public Relations and Research Librarian, as the first librarian to travel to Fudan from North Carolina. Fudan University Library chose Weihau Shi, Deputy Head of the Administrative office and Secretary of University Librarian in Fudan University Library, to travel to Boone, North Carolina to serve in residence at Belk Library in the spring and summer of 2010. Dr. Xiaorong Shao, a Chinese native who has been a diversity faculty fellow librarian at Appalachian State University since 2006, coordinates the librarian exchange program between Fudan University and Appalachian State University.

In the fall of 2009, Megan Johnson, accompanied by Weihua Shi, visited all of Fudan's five libraries to allow Johnson to gain a wider perspective of Chinese libraries, and also visited several other major libraries in Shanghai, including East China Normal University, Shanghai Jiaotong University, TongJi University Library, and Shanghai Public Library. Additionally, they visited several departmental libraries at Fudan University, including the Management School 
Library and the International Culture Exchange School library. At the Liberal Arts Library, Johnson met with the cataloging, periodicals and reference departments. Johnson spent a week with the reference department at the Liberal Arts Library (which is a centralized department, serving all FDU libraries) learning about their services.

Johnson and Shi gave two presentations with librarians from many Shanghai institutions in attendance. Their first presentation focused on the instruction program at the Belk Library and Information Commons, while the second presentation covered Belk Library's recent innovations in customer service. In late summer 2010, Shi and Johnson will present at Appalachian on lessons learned through the exchange and plans for implementation of new ideas gathered (at time of submission, this presentation has not yet taken place).

\section{Institutional overviews}

Fudan University in Shanghai, China is one of the top five comprehensive universities in China. It is highly ranked in humanities, social sciences, medicine, mathematics, bioscience, chemical science and physical sciences. Fudan University has four campuses (Handan, Fenglin, Zhangjiang, and Jiangwan) with a total enrollment of 26,792 on-campus full-time degree candidates. Fudan has 20,670 continuing education and online education students. Fudan confers doctoral degrees in 24 level-one and 153 level-two academic disciplines, master's degrees in 225 disciplines and bachelor's degrees in 70 disciplines. Fudan also has 25 research stations that offer post-doctoral research programs (Fudan University Homepage, 2010).

Located in Boone, North Carolina, Appalachian State University (ASU) is a Carnegie Class "Master's College and University I" and is part of the 17 campus University of North Carolina System, and has almost 17,000 total students enrolled (1500 of these are Distance Learning students). It offers more than 140 undergraduate and graduate major programs. ASU also confers one doctoral degree in educational leadership (Appalachian State University Homepage, 2010).

Fudan University and Appalachian State University have an existing 14-year relationship, known as the William R. Holland Fellows for Business Study. Each year, twelve Appalachian students and twelve Fudan students analyze business case studies in small groups through a semesterlong class called "International Business in China." Fudan students travel to the United States for two weeks in April and Appalachian students visit China during May. This undergraduate student exchange has created a positive association between Fudan University and Appalachian State University. Many business faculty members at both institutions have benefited by leading these student exchanges. In recent years, the partnership between the two 
universities has grown to include several different programs at both institutions; library exchange is a positive result of this expanding relationship.

\section{Library overviews}

Fudan University has five major libraries spread across four campuses: Liberal Arts Library, Science Library, Medical Library, Zhangjing Library, and the Lee Shau Kee Library on the Jiangwan campus. In 2008, the Mathematics Department Library became the first branch library. There are also thirty-two departmental libraries. The libraries of Fudan University have a total staff of 201: six professors, thirty-two associate professors and ninety-four people with medium-level qualifications. For comparison, Appalachian State has a main library and one branch library, the Music Library. Appalachian State University Library employs eighty-seven personnel, forty of whom are library faculty members.

Clearly, Fudan is a much larger university with a bigger library system. However, the exchange program between the libraries could enrich both institutions on a number of levels building upon the strengths of each institution. Appalachian State University and its library have a long tradition of innovation in service and instruction. Fudan has much to share as a major research institution in China and is one of the two national central libraries of the China Academic Social Sciences and Humanities Library (CASHL).

\section{General differences in Chinese and American universities and libraries}

\section{Education system}

The nature of higher education in the United States and in China is culturally different, and this in turn affects the design of their respective library service and instructional programs. The Chinese education system focuses on students acquiring theoretical and factual information while American education places more emphasis on developing students' critical thinking and problem-solving skills. At ASU, professors often ask students to give their opinion orally and in writing. This practice builds a student's writing and rhetoric skills. The library fits into this curriculum by helping students find resources that support the arguments used in their papers and to critically evaluate the information gathered.

In China, university teaching is more lecture-based and textbook centered. Communication tends to more one-way. Chinese college students seldom engage in discussion or cooperative learning activities. Learning exists of memorization of factual information from lectures and textbooks and is driven by exams. This works well for mastering knowledge, but is less effective for encouraging creative abilities and critical thinking. According to Haggis (2003), 
Teaching in China is primarily through lectures, in which students play a passive role during their learning experience. Memorizing is much more the norm, which in the West is linked to lack of understanding. In studies with Chinese students, however, high achieving students appeared to be memorizing in a way that led to understanding, which is associated with a deep approach. The anomaly is called "the Chinese paradox." (p. 93).

At Fudan, critical thinking skills are not emphasized as part of writing instruction to the same degree as in the West, but Fudan's approach may be the most appropriate for Chinese students. Kvan and Jia (2005) state, "it may be that the kind of learning environments and activities which promote effective learning in some cultures may not promote the same outcomes in other cultures where different learning styles predominate" (p. 30).

Perhaps a balance of styles of teaching and learning would promote innovative abilities in the students of both cultures. A recent Newsweek-Intel Global Innovation Survey (McGinn, 2009) indicates that Americans and Chinese parents disagree what skills their children will need. Americans believe their children should improve math and science skills in education, which tend to be associated with rote learning and the memorization of formulas or theorems. Chinese parents are concerned about their children developing creative problem-solving skills, which require critical thinking.

While universities in the U.S. and China may have different emphasis in educational philosophy, their libraries correspondingly support their university's curricular goals and changes. Fudan University started an innovative program in 2005, which uses the "Shu Yuan" style, a Chinese traditional teaching and learning style which advocates small class education, classics, building rhetoric skills, and critical thinking. In this "Fudan Shu Yuan" system, freshman from all disciplines live together and receive a general knowledge education (Ji, 2009). In addition, rapidly growing internationalization, especially through student and faculty exchange programs with the universities in the West, has provided Fudan with opportunities to incorporate new ideas and approaches into its curriculum and instruction methods.

ASU recently overhauled its approach to undergraduate general education with four fundamental goals: Thinking critically and creatively; communicating effectively; making local to global connections; and understanding responsibilities of community membership. Libraries at both institutions seek to evolve their services and instruction efforts to support their institutions' respective initiatives. 


\section{Students' residence}

Another difference in undergraduate education that affects students' use of the library is the location of their residence in relation the library. In China, the university administration acts more "in the place of family." For example, at Fudan, all full-time students live on campus. This applies to all level of students including post-doctoral students. The students all eat at the school-run cafeterias and live in the university dormitories. Although plans are underway to enable off-campus access to online library resources, there currently is no off-campus access to research databases for most students. Consequently, an on-campus wireless network provides Fudan students with all the remote access necessary for library research.

The effect of student residency on library services is much less of an issue at ASU, where two thirds of students live off-campus. Unlike Fudan students, many ASU students live off-campus and often leave on weekends. Consequently ASU students need virtual access to library resources.

\section{Library technology access}

ASU Library and FDUL differ also in equipment access. For example, copiers, printers, and scanners are not as prominent at FDUL. At both Fudan and ASU, the majority of the students have their own computer, and at both institutions, some students carry their own laptops to the library. However, at ASU Library there are 384 computers for students to use and 50 laptops for checkout within the building. There are busy times during the semester when students occupy all of the computers, and as final exams approach each semester, the library opens one of its library instruction rooms to increase the computer supply. ASU students use the computers to write papers, access library resources, search the Internet; check their social networking pages, play games, and more. In the minds of many students, the ASU library functions as a computer lab. Since the new Library and Information Commons opened in 2005, the campus computer labs have reduced hours and stopped providing 24-h service after the library began to remain open for $24 \mathrm{~h}$.

At FDUL there are nearly 500 computers for students to use. However, in the Liberal Arts Library, there is only one bank of computers for students to access electronic library resources, and computers with Internet access are not readily available. In Chinese academic libraries, the majority of students are seen in the reading rooms quietly sitting at desks, studying from books or class notes.

At ASU, a large amount of library staff resources go into maintaining the campus-networked printing system. The printers in the library are the most heavily used on campus. While the 
printing system is technically sophisticated and generally works, the continued need to just load paper for students consumes much of staff's time and attention. In contrast, at the Fudan Liberal Arts Library there are essentially no printers for students to use. If Fudan students want to print they save the articles to a portable drive and then take them to a campus printing station or copy shop.

These differences in equipment access are partly due to difference in resources and partly due to differences in what students expect from the library. Interestingly, before 2008, Fudan Liberal Arts Library had approximately 60 computers, but their use rate proved to be low (only $30-50 \%$ in daytime, $10 \%$ in the evening). In light of this data and because of space issues, FDUL decided the public computers in the Liberal Arts and Science libraries would be set up solely for finding library resources. At the Medical, Jiangwan and Zhangjiang libraries, the computers are set to access to the Internet and for a few other tasks such as word processing. Fudan students also have ready access to a campus computer lab managed by the University's IT department.

The issue of equipment access reflects differences in what services ASU and FDU libraries choose to emphasize. Interestingly, through online suggestion forms students at ASU often request that the library have more computers, particularly laptops, students at FDU do not make such requests. As a cultural observation during her visit to Fudan, Johnson speculated that students at FDU do not seem to exhibit the same sense of entitlement displayed by their American counterparts at ASU. Chinese students just do not seem to expect the library to provide an ever-increasing supply of computers. Aside from the differences in expectations about computer access, students from both institutions comment in the online suggestion boxes on similar issues such as wanting longer library hours, reporting noise, and that the building is either too hot or cold.

\section{Academic status and librarian education}

At ASU, librarians have faculty status and there is a difference in the type of work library faculty members and their staff counterparts perform. For example, as faculty members, ASU librarians are expected to participate in the library's instruction program, to do professional service, and to engage in scholarship. "Tenure track" faculty must have an American Library Association (ALA) accredited master's degree and at minimum, a second advanced degree.

Universities in China do offer programs in library science, both at the undergraduate and master level. Fudan itself has a small but growing library and information science program. Yet, at FDUL the line is not clear between professional librarians and other staff. Many people working as librarians at FDUL do not have a master's degree in library and information science, and are doing work that would be considered within the realm of a professional librarian in the United 
States. Some librarians working at FDUL do have faculty status, especially those who teach classes.

To help with training and orientation to the profession, FDUL has instituted an innovative training program where new hires are brought in with an idea as to which department they will be placed. But for the first nine to twelve months of employment, employees rotate their service (for up to three months) among different departments. This is intended to orient new staff members to the different aspects of the FDUL system. It also is meant to help determine the new employees' strengths and final placement in a particular department. ASU library does not currently have such a training program and generally hires a person to serve in a particular area.

Another difference between the ASU Library and FDUL workforce is the average age of employees. In general, the Chinese retirement age is 55 for women and 60 for men, and the staff tends to be younger at Fudan than at ASU. Additionally, FDUL does not hire as many student employees as ASU, so staff perform tasks such as shelving books that at ASU is usually delegated to students.

\section{Similarities and differences in library services}

\section{Instruction program}

At ASU, almost all instruction sessions (called information literacy sessions) are tied to a particular class and assignment. The library has formalized an information literacy program which is aligned with the university's general education program. In 2008-2009, ASU librarians reached 9458 (two thirds) of the full-time on-campus students with information literacy sessions. Most of these sessions take place in the three classrooms fully equipped with computers for all students located in the Information Commons.

At FDUL, during the 2009 academic year 8884 or $34 \%$ of full-time on-campus students attended a library instruction session. The reference team introduces new students to library services and resources at the beginning of every academic year. Additionally, there are between 30 and 60 sessions in an academic year, mostly on how to use library resources such as MetaLib SFX or a particular database (both Chinese and English language databases). These instruction sessions are not tied to particular classes, but through library outreach, librarians inform instructors of upcoming library sessions, and the instructors encourage their students to attend. The classroom in the Liberal Arts Library has a computer and projector set up for the instructor, but as of this writing the room is not set up with computers for students to follow hands-on. This is also true at the new Lee Shao Kee Library on the Jiangwan campus. But though hands-on 
learning is not emphasized in the classrooms, students can bring their laptops and connect to the databases through wireless access.

In 2009, the Fudan Libraries on four campuses offered over 100 general user-training classes and had over 3000 attendees. Table 1 shows the number of library training classes offered and the number of participants on each campus.

Table 1. Number of General Library User Training Classes at Fudan University Offered by Four Campuses and the Number of Attendees.

\begin{tabular}{|l|l|l|l|l|}
\hline Classes/attendees & Handan (main campus) & Jiangwan & Fenglin & Zhangjiang \\
\hline Spring 2009 & $30 / 730$ & $8 / 340$ & $19 / 493$ & None \\
\hline Fall 2009 & $23 / 841$ & $8 / 364$ & $15 / 276$ & $2 / 40$ \\
\hline
\end{tabular}

Librarians at FUDL also conducted 34 orientation classes for freshmen during the 2009 academic year, with 3600 students participating. The library orientation usually takes place in colleges and departments, and the librarians distribute library flyers and information sheets during the orientation. In 2009, FUDL started a campaign among freshman students, called (translated into English) "Walk into your Library, Learn about your Library." The campaign received 23 requests for library tours, and offered six seminars on library research in different subject areas, with about 900 students involved in the events.

In addition to the level of instruction described above, the "Literature Retrieval Teaching and Research Section" team at Fudan, which is based in the Medical School Library, focuses on fostering the capability of deep information literacy and research initiative literacy. The courses they offer go well beyond basic information literacy instruction. About 1000 students annually take these elective or required courses ( $\mathrm{Li}$, Wang, Fu, \& Xu, 2009). In these semester-long classes, students learn to identify and evaluate resources, and to develop sophisticated search strategies that require critical thinking. These courses lead "students to solve the problem independently through Problem Based Learning (PBL)" (p. 595). A full description of the robust "research innovation literacy" program and an exploration of PBL are described by Li et al. 


\section{Services to faculty}

At Fudan and ASU, collection management and reference librarians do outreach to faculty in a number of ways. They act as liaisons between the library and the university's departments. They visit departmental meetings to discuss services, and send e-mail notifications of new services or new materials. At both libraries, the services to faculty include acquiring materials through purchase, document delivery, or interlibrary loan. Both institutions offer research support for faculty, and put materials on reserve for faculty. Both institutions understand communication with faculty is an important component in a robust information literacy instruction program.

Novelty Search is a unique service for faculty in Chinese academic libraries. Fudan faculty members seldom apply for external funding for research as is expected in American universities, particularly in the sciences. In China, the central government selects specific areas of research to encourage and fund. The Novelty Search service is centrally coordinated in China by the Ministry of Education and is somewhat similar to a patent search. Li (2007) describes this service: "When a researcher wants to apply his research idea, research findings or a patent to practical use, he is required to make a request for a Science and Technology Novelty Evaluation Report" (p. 145). Librarians at FDUL and other major research institutions are trained and receive certification on how to do Novelty Searches. The librarian discusses the topic with the researcher to understand the "novel aspects" of the proposed project. The Novelty Search service is intended to assist the development of scientific research and to avoid duplication. The librarians identify one or more innovative ideas, keywords, and descriptors, and then search electronic databases and printed retrieval tools, basically performing a literature review. $\mathrm{Li}$ (2007) says of the Novelty Search service:

The establishment of the S\&TNS [Novelty Search] service in university libraries has been a significant advance, because it enhances the rigor and standardization of scientific research management in China. Furthermore, it can improve the usage level of university libraries' information resources. (p. 148)

As a counterpoint to Li's assessment, Johnson received anecdotal evidence of problems with Novelty Search from several librarians at FDUL and at Tonji University library. The librarians report that researchers sometimes feel librarians are not knowledgeable enough to assess the novel aspects of research in highly specialized areas such as chemistry, nanotechnology, or other disciplines. Hence the evaluation report prepared by the librarian may not reflect the value of the proposed research. Also, in some cases, the research may be so innovative that no other published research yet exists. 
Another major reference service the FDUL provides to faculty - that ASU librarians only voluntarily and only occasionally assist faculty members with - is providing a report on citation impact analysis of individual faculty research. Faculty members in Chinese universities do not go through a tenure process like their American counterparts, but their work toward promotions and pay increases has comparable processes.

The citation and impact report the FDUL reference librarians create, which analyzes a faculty member's academic research, can have a real effect on a professor's evaluation. Although not directly related to Chinese libraries, Corby (2001) provides an overview of the potential inequities of citation analysis in relation to faculty evaluation. In general, not all important research is going to have citations generated in Web of Science Journals (the standard for traditional citation and impact analysis in the West) and, moreover, many professors have argued that library staff may not be qualified to comment on faculty impact in specialized fields. Citation tools like those found in Web of Science are powerful; however, they are imperfect tools for fully evaluating the scholarly impact of an author. Librarians at ASU may help faculty learn how to use citation databases and some have helped faculty members build citation records; however, unlike their counterparts at FDUL, their role is assistive and advisory rather than evaluative.

\section{Services to students}

At FDUL students get reference assistance with questions either in-person, through an online chat service, or via phone, etc. If the reference librarian cannot fully answer the question at that time, the librarian takes their contact information and sends a more complete answer later by email or phone. ASU library provides these three types of reference services as well as an additional more formal opportunity for one-on-one consultation with a librarian through the Research Advisory Program (RAP). Students use an online form to request a session with a librarian, and then a librarian picks up the request and prepares for the appointment based on the stated research needs of the student. During a RAP session, students meet with a librarian for $30 \mathrm{~min}$ to an hour for in-depth research assistance to identify appropriate sources for a research topic. A total of 353 ASU students used a RAP session during the 2008-2009 academic year. ASU distance learning students have the opportunity for a RAP session with a librarian using an online system that provides assistance via the web.

Some other services to students at ASU library that are not currently available at Fudan's libraries include: a 24-h library between Sunday and Friday nights during the Fall and Spring semesters; an assistive technology room for students with different types of disabilities; equipment checkout (including laptops and video cameras); and six book drops across campus. 
Another service asset at ASU not yet found at FDUL is the Digital Media Studio (DMS). The DMS serves the entire university community with the mission of empowering users to create quality digital projects. The use of the studio is not limited to classroom assignments and personal projects are encouraged. It is a hands-on learning lab where users master the foundations that will help them succeed in content creation independently. The equipment in the studio is cutting edge and includes three top of the line Mac Pros and video capture decks for Macintosh G5s. Also, students and faculty can check out high-end digital equipment like video cameras, tripods, and sound recorders.

Several recent service initiatives have helped improve customer service at ASU. To keep track of all types of questions asked at public service points in the library, the ASU systems team designed a service statistics database that records the type and time of questions asked. In addition to keeping accurate statistics, this helps determine appropriate staffing levels during operating hours.

The technical support staff has also made improvements that benefit service at ASU Library. For example, they have implemented the use of walkie-talkies to communicate throughout the building. They also provide technical support via instant messaging to all the public service points in the library.

\section{Services to continuing education/distance learning students}

Fudan has 20,670 continuing education and online education students. That is close to the same number of full-time, on-campus students at Fudan. Most online students take classes online or in a learning centre. Fudan University does not charge their continuing education and online education students a fee for library access, and they simply have no library privileges or access. This is acceptable due to the nature of much of the lecture and textbook-based coursework which usually does not require them to use library resources. Additionally, all residents of Shanghai have access to an excellent public library system.

In contrast, ASU has about 1500 Distance Learning students (about $10 \%$ of the total student population). At ASU, in line with the Association of College and Research Library (ACRL) Standards for Distance Learning Library Services (2008), the philosophy is to ensure library access equivalent to that of their on-campus classmates. ASU library receives funding in the university budget that is earmarked for the delivery of programs to off-campus students. Some of the distance education classes taught at ASU take place in an online virtual world. The distance-learning librarians are active in creating a virtual library and participating in classes in this online world, providing reference service and information literacy instruction (Johnson, Ochoa, \& Purpur, 2007). 


\section{Research guides and tutorials}

Web tools such as research guides and tutorials supplement classroom instruction. At ASU, there are about 100 research guides created using a web-based service called LibGuides. ASU also has an online information literacy tutorial with six modules covering: library services, information sources, search strategy, finding library materials, evaluating information sources, and avoiding plagiarism. (See details at http://library.appstate.edu/tutorial). At ASU, librarians also collaborate with the faculty in the online course management system, Moodle (locally branded as "AsULearn"). By comparison the Fudan librarians have created two topic guides, and are evaluating how to proceed with the project.

\section{Assessment measures}

All libraries struggle with valid assessment measures and tools for user feedback. Both ASU library and FDUL have online and paper suggestion forums. More formally, both libraries use the LibQUAL+ ${ }^{\mathrm{TM}}$ assessment instrument. ASU library completed its first LibQUAL+ ${ }^{\mathrm{TM}}$ survey in 2006 and repeated the process in 2008. FDUL completed its first survey in 2009. LibQUAL+ TM is one of the few international standard benchmark tools libraries have, and with analysis, the data and comments from LibQUAL+TM can help libraries formulate future plans and strategic direction. The LibQUAL+ ${ }^{\mathrm{TM}}$ summary radar charts demonstrate similarities between the two institutions. Fig. 1 is from ASU's 2008 LibQUAL+TM results; Fig. 2 is FDUL's 2009 LibQUAL+TM results. They are plotted somewhat differently, but both provide information on user perceptions of the library's information control, effect of service, and the library as place. At neither institution do users "perceive less than the minimum" in any of these areas. There are also no areas at either institution where the libraries exceed users' expectations to a "greater than desired" degree. Librarians can use this data to improve services and then re-do the survey to see if progress has been made. For example, ASU's 2008 chart shows that access to e-resources is "less than desired." At FDUL, point 10 reflects a period of dissatisfaction with the OPAC system as it was undergoing a change. To address these issues, ASU is doing web usability studies and research into discovery tools, and FDUL enhanced their training on the OPAC system and improved online tutorials ([Viles, 2008] and [Zhang et al., 2009]). 


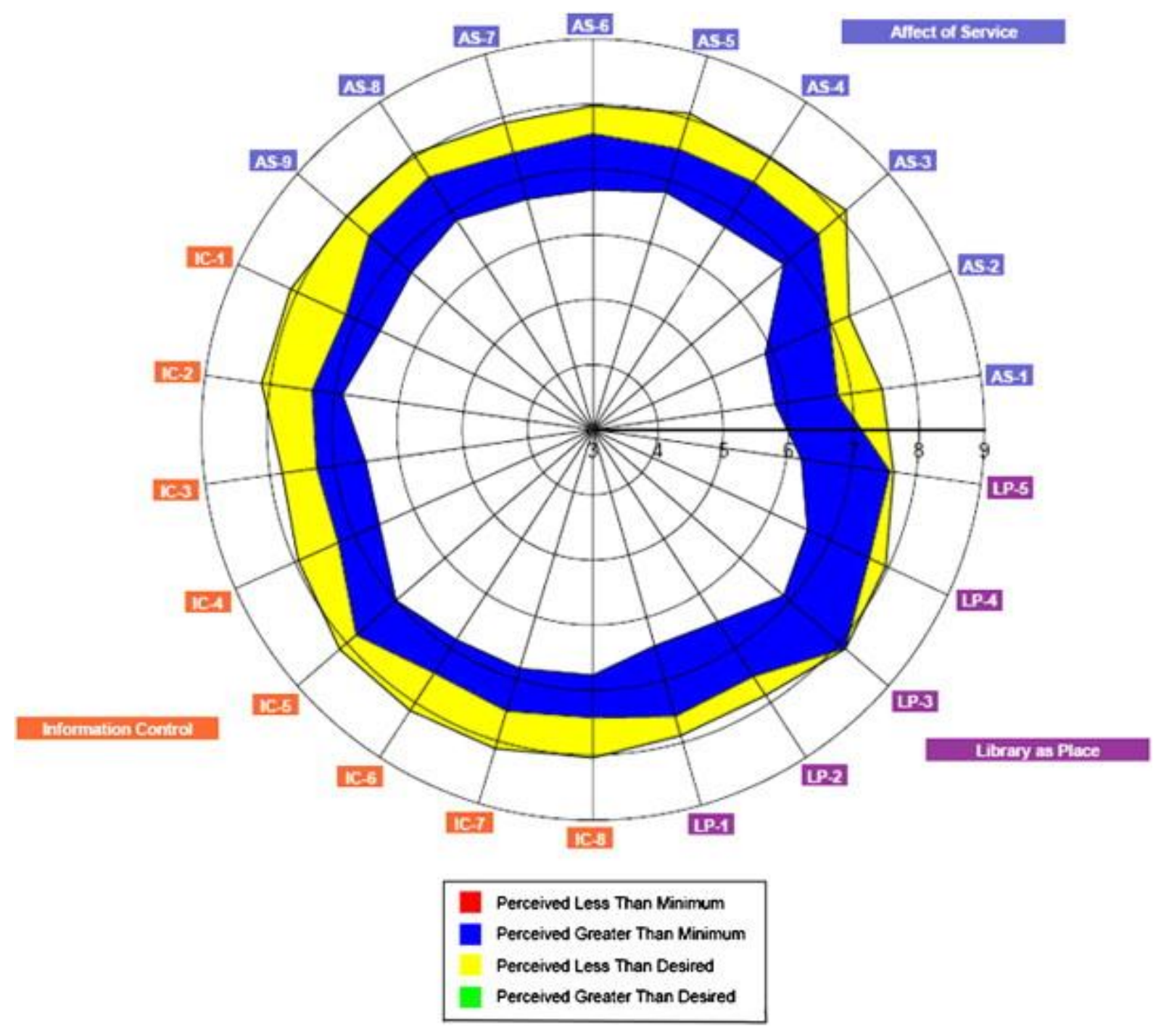

Figure 1. ASU 2008 LibQUAL+ $^{\mathrm{TM}}$ results. 


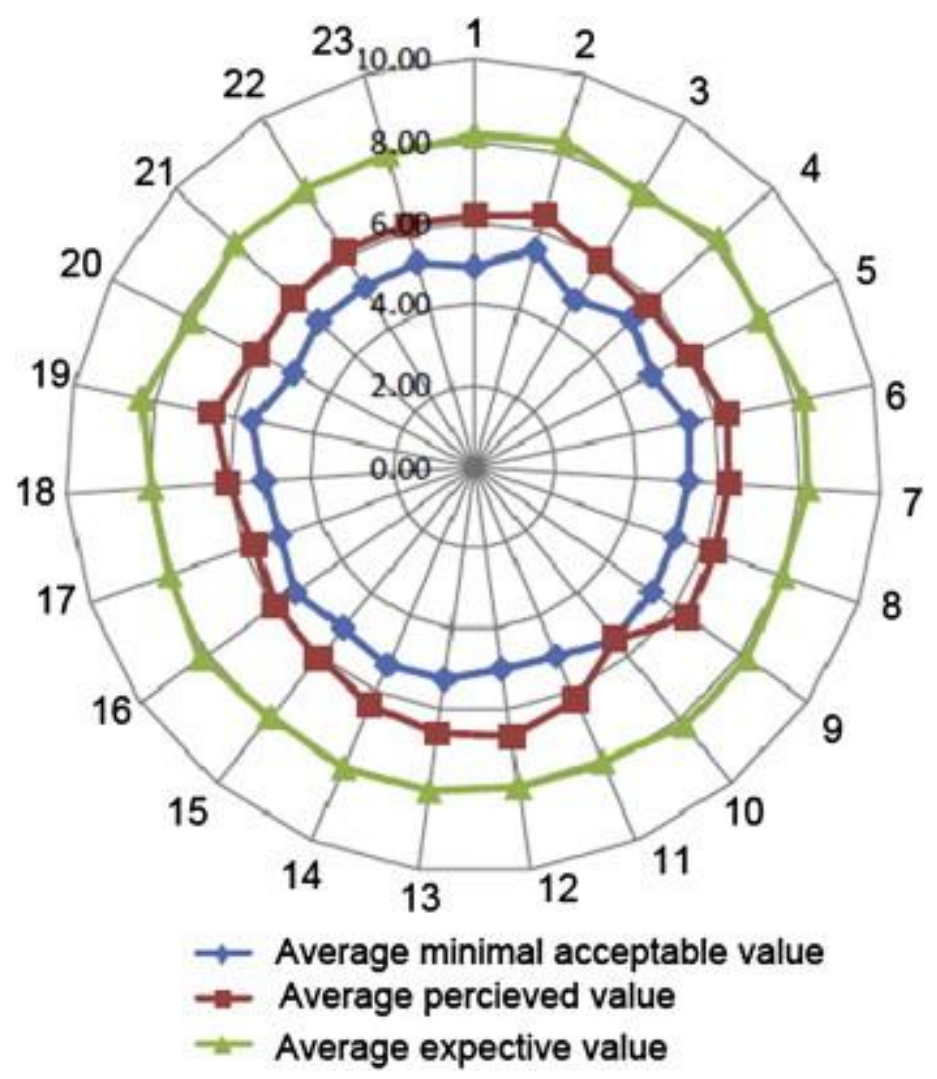

Figure 2. FDUL 2009 LibQUAL+ ${ }^{\mathrm{TM}}$ results.

Another assessment tool ASU began to develop in 2009 is the Balanced Scorecard system, which allows the library to organize and report evaluation and assessment on its website. The Balanced Scorecard model "balances" four unique perspectives to inform strategic decisions. The perspectives are: the patron; financial; internal process; and learning and growth. The Balanced Scorecard model provides a measurement framework to align mission and strategy with consensus driven goals.

\section{Service innovations, success factors and challenges}

Fostering innovation is a challenge for any institution. Both ASU and FDUL library systems value innovation and improvement, yet each has its own approach and areas of emphasis.

The most important elements of successful innovation in service at ASU library are: administrative support, open communication, and a workplace culture that encourages experimentation. It is essential that library staff feel the library administration supports their 
efforts to provide excellent customer service, and that employees understand everything is subject to change. Staff need to feel they can experiment and that even failure is Okay! Service is always "a work in progress."

On the other hand, one of the challenges to providing excellent service is simply that change is hard. Staff can feel threatened by constant change, and even if it is culturally acceptable to have an innovation fail, failure is not a pleasant experience. Another ongoing challenge to providing service is that it can be difficult to communicate effectively with patrons. We live in a world of information overload, and often people do not realize they need quality information and library services until the last minute. The research process has gotten easier since online searching has become possible, but "instant" and "quality" service are not always synonymous.

Another challenge to providing services is determining appropriate training levels. At ASU, there is concern about what is expected of staff members and what "professional" librarians are required to do. FDUL has less angst on this issue; creative leadership is welcomed from all staff members and there is less concern, for example, about if it is "suitable" for a staff person to teach a workshop on how to use library resources.

Expectations are also a challenge. For example, students in both the United States and China can misunderstand what is available on the Internet. They commonly believe that everything they need is on the Internet. A quote from a student in ASU's LibQUAL+ ${ }^{\mathrm{TM}} 2008$ comments section demonstrates this, "As far as resources go, the only reason I use the library is because a professor requires it. I am very capable of distinguishing correct information versus misinformation that I find online and do not require the services of the library to do that. I'd venture to say the library is only necessary because professors require it, and some students don't have computers. Otherwise, all research and information is available on the Internet 24/7 in a matter of milliseconds" (Viles, 2008).

FDUL is proud of its rich collection in the humanities and social sciences, especially in the areas of Chinese history and philosophy. FDUL has diligently tried to provide ever better service for patrons. However, FDUL has many challenges to face. One of these is the new burden of managing multi-campus university libraries. Before 2002, Fudan University only had two libraries (the Liberal Arts Library and Science Library) on the Handan Campus. In 2002, First Medical University merged with Fudan University which brought on a "new" Medical Library to FDUL. Two new campuses, each with a library, were added in 2005 and 2008 (Zhangjiang Library and Lee Shau Kee Library on the Jiangwan campus respectively). At each of these locations, patrons have different needs due to the different curriculums (law, medicine, engineering, etc.). These rapid changes have required FDUL to think creatively and evolve quickly. 
How to staff these libraries with employees who have the correct mix of skills in technology, subject area expertise, and an open service attitude is also a challenge, especially given the lack of experienced professionals. Many employees have a subject expertise, but enter the FDUL system with no background in library science. Training these employees and placing them on the right team takes time and effort. Also, keeping up with emerging technologies in libraries requires its own commitment of time and resources in developing applications and training staff.

\section{Conclusion}

International librarian exchanges for short and long-term periods are not a new concept. For years, librarians have traveled for professional development and to lend or gain expertise. These exchanges are a form of library faculty development that leads to better support for international students and faculty at their home campuses. It also sparks a global exchange of ideas and builds cultural understanding.

The three-year Fudan-Appalachian Exchange Program Agreement (FALEP) is based on the premise that refined understandings of library services, resources and operational systems in both China and the United States will help develop better strategies and facilitate improvements for libraries in both systems. The experience from the first exchange librarian to Fudan from ASU has proved that FALEP benefits both institutions in several ways.

Both libraries hope to improve their services to international students and scholars by learning from each other's experience. ASU can deepen its approach to information literacy instruction by studying the Research Innovation Literacy program at FDUL's Medical Library. ASU can also examine their services, such as managing printers and being the largest computer laboratory on campus, asking if such services should remain core library services. FDUL can choose to expand selected services and borrow ideas from ASU. Some of the results of librarian exchanges are intangibles, and it is hard to quantify exactly how a faculty member has "developed" as a result of an international exchange, but there is no doubt that the experience broadens one's understanding of the world. By building relationships across borders with our fellow librarians we open up dialogues that expose us to different ways of doing our jobs and providing service. These discussions of mutual concerns enrich us both personally and professionally and enhance the world of librarianship. 


\section{References}

Appalachian State University Homepage, 2010 Appalachian State University Homepage, About section Retrieved December 6, 2010, from http://www.appstate.edu/about (2010).

ACRL, 2008 Association of College and Research Libraries (ACRL), Standards for distance learning library services Retrieved July 2, 2010, from

http://www.ala.org/ala/mgrps/divs/acrl/standards/guidelinesdistancelearning (2008).

Chen, 2006 L. Chen, Library public services in China, Journal of Library Science in China 32 (1) (2006), pp. 5-12.

Chen and Liu, 2005 S. Chen and J. Liu, Using libraries in China, College \& Research Libraries News 66 (2) (2005), pp. 124-130.

Corby, 2001 K. Corby, Method or madness? Educational research and citation prestige, Libraries and the Academy 1 (3) (2001), pp. 279-288.

Fudan University Homepage, 2010 Fudan University Homepage, About section Retrieved January 6, 2010, from http://www.fudan.edu.cn/new_genview/genview.htm (2010).

Haggis, 2003 T. Haggis, Constructing images of ourselves? A critical investigation into "approaches to learning" research in higher education, British Educational Research Journal 29 (1) (2003), pp. 89-104

Ji, 2009 L. Ji, Change of educational model caused by teaching reforms at Fudan, Education Newspaper of China (2009, July 15) July 15, 2009 (in Chinese).

Jiao et al., 2009 S. Jiao, F. Zhuo, L. Zhou and X. Zhou, Chinese academic libraries from the perspective of international students studying in China, The International Information \& Library Review 41 (1) (2009), pp. 1-11.

Johnson et al., 2007 M. Johnson, L. Ochoa and G. Purpur, Virtually usable: a test of the information gardens, The Journal of Academic Librarianship 33 (5) (2007), pp. 593-601.

Kvan and Jia, 2005 T. Kvan and Y. Jia, Students' learning styles and their correlation with performance in architectural design studio, Design Studies 26 (1) (2005), pp. 19-34.

Li, 2007 A. Li, A kind of transformation of information service-science and technology novelty search in Chinese university libraries, The Journal of Academic Librarianship 33 (1) (2007), pp. 144-148.

Li et al., 2009 X. Li, Y. Wang, L. Fu and M. Xu, The university library: incubation center of research innovation literacy, The Electronic Library 27 (4) (2009), pp. 588-600. 
Liao, $2004 \mathrm{~J}$. Liao, A historical perspective: the root cause for the underdevelopment of user services in Chinese academic libraries, The Journal of Academic Librarianship 30 (2) (2004), pp. $109-115$.

McGinn, 2009 D. McGinn, East beats west, Newsweek (2009, November 23) Retrieved November 27, 2009, from http://www.newsweek.com/id/222979.

Scherlen, A., , X. Shao and E. Cramer 2009 Bridges to China: developing partnerships between serials librarians in the United States and China, Serials Review 35 (2) (2009), pp. 75-79.

Viles, 2008 A. Viles, Report on the 2008 LIBQUAL+ ${ }^{\text {TM }}$ results. Internal document, Appalachian State University Library, Boone, NC (2008).

Wu and Huang, $2003 \mathrm{~J}$. Wu and R. Huang, The academic library development in China, The Journal of Academic Librarianship 29 (4) (2003), pp. 249-253.

Zhang et al., 2009 M. Zhang, L. Xie, C. Shao and Y. Xie, Library service evaluation and improvement based on LibQual results, Research on Library \& Information Work of Shanghai Colleges and Libraries 4 (2009), pp. 1-5. 